\title{
How Berkeley's Gardener Knows his Cherry Tree*
}

\author{
Kenneth L. Pearce \\ Trinity College Dublin
}

\begin{abstract}
The defense of common sense in Berkeley's Three Dialogues is, first and foremost, a defense of the gardener's claim to know his cherry tree, a claim threatened by both Cartesian and Lockean philosophy. Berkeley's defense of the gardener's knowledge depends on his claim that the being of a cherry tree consists in its being perceived. This is not something the gardener believes; rather, it is a philosophical analysis of the rules unreflectively followed by the gardener in his use of the word 'exists'. It is by following these rules that the gardener gains knowledge of the cherry tree. Uncovering these deep connections between Berkeley's epistemology and his philosophy of language and placing them in the context of his critique of both Cartesian and Lockean philosophy will clarify Berkeley's strategy for bringing his reader back to common sense and practical engagement in the ordinary affairs of life.
\end{abstract}

George Berkeley often frames his philosophy as a defense of common sense against skepticism. One of the core tenets of that philosophy is that the esse of bodies is percipi (PHK, §3), i.e., that "the very existence of [a body] consists in being perceived" ( $\S 88)$. This appears to commit Berkeley to the claim that the person of common sense believes that physical objects are nothing over and above ideas (Pappas 1982,18). However, this claim is implausible in the extreme and is inconsistent with many of Berkeley's other remarks, including his claim that his philosophy is a novel discovery (N, §491; PHK, Preface) and his admission that the denial of the esse is percipi thesis is "an opinion strangely prevailing among men" (PHK, §4). ${ }^{1}$

In Berkeley's Three Dialogues between Hylas and Philonous, naive common sense is represented in the person of the gardener. Berkeley's defense of common sense is, first and foremost, a defense of the gardener's claim to know that a cherry tree does, and an orange tree does not, exist in the garden (DHP, 234). In this paper, I argue that Berkeley's central aim is not to secure the gardener's knowledge, but to show that the gardener's knowledge had been secure all along.

${ }^{*}$ This is the author's preprint version of an article accepted for publication by Pacific Philosophical Quarterly. For citation purposes, please use the version of record, available (with subscription) at: http://onlinelibrary.wiley.com/doi/10.1111/papq.12199/full.

1. 'Strangely' here means 'strongly' (Winkler 1989, 5). On Berkeley's frequent confessions of conflict with 'vulgar' beliefs, see Bordner 2011, 316-318. 
Through the corrosive influence of Cartesian and Lockean philosophy, Hylas ends up "being ignorant of what everybody else," including the philosophically naive gardener, "knows perfectly well" (DHP, 229). If corrupted philosophers are to recover their lost knowledge of cherry trees, they must learn to imitate the gardener's virtuous epistemic practice of trusting his senses. ${ }^{2}$ Philonous's strategy for defending the gardener's practice is to argue that the rules governing the proper use of the word 'exists' in English guarantee that that word is correctly applied to all presently perceived objects. The gardener follows these rules without being able to state them, but if the corrupted philosophers are to be saved the rules will have to be stated and defended explicitly. This is a key element of Berkeley's philosophical project.

Descartes held that radical doubt was necessary as part of a philosophical project that "does not involve action but merely the acquisition of knowledge" (CSM, 2:15). According to Berkeley, once we recognize that "words ... were framed by the vulgar, merely for conveniency and dispatch in the common actions of life, without regard for speculation" (DHP, 246) we will come to see that there is no standpoint of pure speculation which the philosopher can occupy in order to criticize the gardener. Language, meaning, truth, and knowledge, Berkeley holds, all find their home in 'the common actions of life' - a place where philosophical skepticism finds no purchase.

In $\S 1$ I examine Berkeley's conception of the skeptical problem. In $\S 2$ I outline Berkeley's strategy for dissolving the skeptical problem by attention to the rules of use in ordinary language. This interpretation is apt to strike many readers as anachronistic. I therefore proceed, in $\S 3$, to situate Berkeley's line of thought in the context of the epistemology of his 17th century predecessors and show, in $\S 4$, how a reading of Berkeley's text against this backdrop does indeed support my interpretation. I conclude, in $\S 5$, by showing in detail how this interpretation provides a defense of the gardener's claim to know the cherry tree.

\section{The Skeptical Problem}

It has often been assumed that the primary or only target of Berkeley's antiskeptical arguments was Locke. This assumption, however, runs directly contrary to Berkeley's own framing of his anti-skeptical project in the front matter of the Principles and Dialogues, where Berkeley claims that "the common principles of the philosophers" (DHP, 167) have "introduced ... doubtfulness and uncertainty ... into the several sects of philosophy" (PHK, Intro §4). Berkeley's account of these principles does contain allusions to Locke, but it also contains a great many allusions to Cartesianism. ${ }^{3}$ What this shows is that the skepti-

2. This thesis - that the epistemic practice of trusting one's senses is the primary thing Berkeley means by 'common sense' in the Three Dialogues - is consistent with but does not presuppose the more general thesis (defended by Holtzman 2013) that 'common sense' for Berkeley is the proper use of one's faculties.

3. The Cartesian background of some of Berkeley's anti-skeptical arguments is emphasized by Atherton 1991, though that paper is focused specifically on issues about the aims and 
cal principles Berkeley aims to uncover and refute must be sought not among Locke's distinctive doctrines but rather among the principles that are agreed upon between (at least) Locke and the Cartesians. The fundamental principle Berkeley identifies is the distinction between a sensible object's real nature and its outward appearance. Closely connected to this is another dichotomy Berkeley seeks to undermine: the distinction between speculative (i.e., theoretical) and practical knowledge.

The Introduction to the Principles opens with the observation that

the illiterate bulk of mankind that walk the high-road of plain, common sense ... are out of all danger of becoming sceptics. But no sooner do we depart from sense and instinct to follow the light of a superior principle, to reason, meditate, and reflect on the nature of things, but a thousand scruples spring up in our minds, concerning those things which before we seemed fully to comprehend (PHK, Intro $§ 1)$.

Berkeley's talk of "depart[ing] from sense and instinct to follow the light of a superior principle" is a clear reference to Cartesianism, and this reference is reinforced by his use of the word 'meditate' immediately thereafter. In the Synopsis of the Meditations, Descartes had written that "the greatest benefit [of the method of doubt] lies in ... providing the easiest route by which the mind may be led away from the senses" (CSM, 2:9). As is often the case, Malebranche, the Cartesian philosopher with whom Berkeley was most familiar, is more emphatic: "your senses beguile you infinitely more than you can imagine ... Reason must always remain in charge of our discussion" (Malebranche [1688] 1997, 4).

The Cartesian project begins by casting doubt on the senses. The aim of this doubt is to lead us to a 'superior principle,' the faculty of pure reason. Thus Descartes argues in the Sixth Meditation that from "the very fact that God is not a deceiver" I am assured of "the impossibility of there being any falsity in my opinions which cannot be corrected by some other faculty" (CSM, 2:55-56, emphasis added). The senses are in constant need of correction and the faculty capable of correcting them is the faculty of pure reason.

Among the most important corrections pure reason must make to the senses is the rejection of beliefs such as:

that the heat in a body is something exactly resembling the idea of heat which is in me; or that when a body is white or green, the selfsame whiteness or greenness which I perceive through my senses is present in the body; or that in a body which is bitter or sweet there is the selfsame taste which I experience, and so on (2:56-57).

Again, Malebranche is characteristically emphatic:

our eyes represent colors to us on the surface of bodies and light in the air and in the sun; our ears make us hear sounds as if spread

methodology of natural philosophy. 
out through the air and in the resounding bodies; and if we believe what the other senses report, heat will be in fire, sweetness will be in sugar, musk will have an odor, and all the sensible qualities will be in the bodies that seem to exude or diffuse them. Yet it is certain ... that all these qualities do not exist outside the soul that perceives them (Malebranche [1674-1675] 1997, 569; cf. 201).

These are the philosophers Berkeley has in mind when he writes in his notebooks, "there are [some] who Say the Wall is not white, the fire is not hot \&c We Irish men cannot attain to these truths" (N, §392; cf. DHP, 229-230, 243-244). ${ }^{4}$ According to their view, the senses represent sensible qualities as really existing in bodies, but a 'superior principle,' the faculty of pure reason, corrects the senses by showing that only modes of extension can be real, objective features of bodies.

The Cartesian doctrine of the unreality of secondary qualities is very likely among the anti-commonsensical views Berkeley has in mind when he says that, once we begin to meditate,

Prejudices and errors of the senses do from all parts discover themselves to our view; and endeavouring to correct these by reason, we are insensibly drawn into uncouth paradoxes, difficulties, and inconsistencies, which multiply and grow upon us as we advance in speculation; till at length, having wandered through many intricate mazes, we find our selves just where we were, or, which is worse, sit down in a forlorn scepticism (PHK, Intro §1).

It is only at the end of this quotation that Locke enters the picture for the first time. Locke had argued that the Cartesian project could not possibly succeed because it rested on an over-optimistic estimate of our faculties. According to Locke, there is no faculty of pure intellect to correct the senses. Accordingly, if the senses misinform us, or do not inform us at all, about some topic, "the busy Mind of man" must simply "stop, when it is at the utmost Extent of its Tether; and ... sit down in a quiet Ignorance of those Things, which, upon Examination, are found to be beyond the reach of our Capacities" (EHU, §1.1.4, emphasis added). ${ }^{5}$ Thus once the 'prejudices and errors of the senses' are discovered, we have only two options: we may either endeavor to correct the senses by reason, or we may confess our ignorance, i.e., (as Berkeley sees things) lapse into skepticism.

4. Berkeley's attack on the primary/secondary quality distinction is often seen as directed at Locke. However, Locke, following Boyle ([1666] 1991, 30-37), holds that whiteness is a power to cause a certain kind of idea, and that power really is in the wall (see EHU, $\S \S 2.8 .10$, 14). This contrasts with the Cartesian view (stated in its most blunt and unqualified form by Malebranche) that sensible qualities like whiteness do not exist in external objects. The view Berkeley discusses, both in the notebooks and the published works, is the Cartesian one, not the Lockean one. See Wilson 1982, 112-116; McCann 1994, 62-63; Rickless 2013, 124; Pearce 2016, 2.

5. In Locke's view, there need not be anything 'forlorn' about our ignorance. For a fascinating discussion of Berkeley's 'forlorn' attitude to skepticism, see Berman 2010. 
As Berkeley correctly observes, his predecessors in the 'modern' philosophy are agreed on the origin of this dilemma: "It is said that the faculties we have are few, and those designed by nature for the support and comfort of life, and not to penetrate into the inward essence and constitution of things" (PHK, Intro §2). Descartes, Malebranche, and Locke all agree (as do many other 17th century philosophers) that God has given us our senses primarily for practical, rather than theoretical purposes (see, e.g., CSM, 2:57-58; Malebranche [1688] 1997, 4; EHU, §1.1.5). The remark about our ignorance of "the inward essence and constitution of things" is a clear reference to Locke's denial of knowledge of real essences (see, e.g., EHU, §3.6.9). However, it should be noted that the Cartesians also denied that the senses could confer knowledge of the natures or essences of things (CSM, 2:21; Malebranche [1674-1675] 1997, 237; [1688] 1997, dialogues 1 and 5).

This series of references to the Cartesians and Locke is the lead-up to Berkeley's famous remark that "the far greater part, if not all, of those difficulties which have hitherto amused philosophers, and blocked up the way to knowledge, are entirely owing to our selves. That we have first raised a dust, and then complain, we cannot see" (PHK, Intro $§ 3$ ). Berkeley then characterizes the project of the Principles as an attempt to "discover what those principles are, which have introduced all that doubtfulness and uncertainty, those absurdities and contradictions into the several sects of philosophy" (Intro §4). This reference to 'several sects,' together with the many swipes at the Cartesians we have already noted, makes it clear that Locke is not Berkeley's only target, and renders doubtful even the claim that Locke is Berkeley's primary target.

The fundamental principle Berkeley identifies in the body of the Principles as leading to skepticism is the view "that there is in each object an inward essence, which is the source whence its discernible qualities flow" (§102). This view is common ground between the Cartesians and Locke. Berkeley rejects this distinction between outward appearances ('discernible qualities') and inward essences in its entirety: "What you call the empty forms and outside of things seems to me the very things themselves" (DHP, 244; see Atherton 1991).

The distinction between outward appearances and inward essences is closely related to the distinction between practical and speculative knowledge, which Berkeley also rejects. The Cartesians and Locke held that the senses give us knowledge of the outward appearances of things which is the sort of knowledge necessary for "the support and comfort of life" (PHK, Intro §2), while speculative (scientific) knowledge would be knowledge of inward essences. In the Principles, Berkley discusses "The two great provinces of speculative science ... natural philosophy and mathematics" (\$101). He argues that the aim of natural philosophy (i.e., what we now call natural science) is "to make the several parts of the Creation ... subservient to the ends they were designed for, God's glory, and the sustenation and comfort of our selves and fellow-creatures" (§109). Similarly, "the entire science of numbers is subordinate to practice" ( $(120)$ : "In arithmetic ... we regard not the things but the signs, which nevertheless are not regarded for their own sake, but because they direct us how to act with relation to things and dispose rightly of them" $(\S 122)$. Berkeley agrees with the Carte- 
sians and Locke that the senses gives us knowledge of outward appearances for practical purposes. Berkeley's radical claim is that this is all the knowledge of nature there is or possibly could be (cf. DHP, 244-246).

Turning now to the Preface to the Three Dialogues, we find that Berkeley paints a very similar picture:

Though it seems the general opinion of the world, no less than the design of providence, that the end of speculation be practice ... yet those who are most addicted to speculative studies seem as generally of another mind ... Upon the common principles of philosophers, we are not assured of the existence of things from their being perceived. And we are taught to distinguish their real nature from that which falls under the senses. Hence arise scepticism and paradoxes. It is not enough that we see and feel, that we taste and smell a thing. Its true nature, its absolute external entity, is still concealed. We spend our lives in doubting those things which other men evidently know, and believing those things which they laugh at and despise (167).

Regarding this passage, note three things. First, Berkeley identifies the culprit as 'the common principles of philosophers.' In light of our discussion so far, it should be clear that he means to refer to 'principles' which are agreed upon among (at least) the Cartesians and Locke. Second, as we have already observed, the key principle Berkeley identifies - the distinction between objects' sensible appearances and their 'real nature,' together with the associated separation between speculation and practice - is indeed such a point of agreement. Third and finally, note that the things which the philosophers doubt on the basis of these principles are "things which other men evidently know." The mistaken distinction between outward appearance and inward essence makes philosophy destructive rather than productive of knowledge, so that those who have philosophized less know more! ${ }^{6}$

Berkeley goes on to say that he, like Locke, is endeavoring to "divert the busy mind of man from vain researches" (DHP, 167; cf. EHU, §1.1.4); however, whereas Locke's 'diversion' aimed to prevent us from wasting our time inquiring into things we cannot know, Berkeley aims to prevent us from wasting our time inquiring into things we already know. ${ }^{7}$ Thus Berkeley writes: "If the principles, which I here endeavour to propagate, are admitted for true ... speculation [will be] referred to practice, and men [will be] reduced from paradoxes to common sense" (DHP, 168). It is the philosophers who are involved in 'paradoxes' and hence it is they who must be 'reduced' to common sense.

Berkeley continues:

6. This sentiment is also expressed at N, §747. For discussion, see Bordner 2011, $\S \S 2-3$; Holtzman 2013. Interestingly, Descartes levels essentially the same charge against Scholastic philosophy (CSM, 1:10-12).

7. That is, things we already know at the beginning of our inquiry. The accusation against the philosophers is that conducting our inquiry badly may actually result in our ceasing to know these things. 
And although it may, perhaps, seem an uneasy reflection to some, that when they have taken a circuit through so many refined and unvulgar notions, they should at last come to think like other men: yet, methinks, this return to the simple dictates of nature, after having wandered through the wild mazes of philosophy, is not unpleasant (DHP, 168).

This passage describes the story arc of the Three Dialogues. The first dialogue sets the reader wandering 'the wild mazes of philosophy,' but Berkeley aims, in the end, to bring us safely home by showing that "the same principles which at first view lead to scepticism, pursued to a certain point, bring men back to common sense" (263). The character who travels on this philosophical journey is Hylas. Philonous is, of course, his guide. A third character in the dialogue is also of importance, but has been overlooked due to the brevity of his appearance. This is the gardener, the proverbial 'person in the street,' who is not lost in the wild mazes simply because he has never left home. Berkeley's aim is that Hylas, and the reader, "should at last come to think like other men," i.e., like the gardener. As I will argue below, Berkeley's aim is not (or at least not primarily) that we should return to having the same beliefs as the gardener, ${ }^{8}$ but rather that we should return to the gardener's epistemic practice of naive trust in the senses. However, if Berkeley is to defend this practice, it is insufficient to prove, as Descartes tried to do, that one can justifiably trust the senses (in however limited a way) on the basis of a sophisticated philosophical argument. Instead, Berkeley must show that the gardener was justified all along, despite having engaged in no philosophical reflection at all.

\section{Berkeley's Anti-Skeptical Strategy}

The gardener makes his explicit appearance in the Three Dialogues in a direct response to the objection with which we began, namely, the claim that the person of common sense does not believe the esse is percipi principle (henceforth 'EIP'). As Hylas puts it, "Ask the first man you meet, and he shall tell you: 'to be perceived' is one thing, and 'to exist' another." Philonous responds as follows:

I am content, Hylas, to appeal to the common sense of the world for the truth of my notion. Ask the gardener why he thinks yonder cherry tree exists in the garden, and he shall tell you, because he sees and feels it; in a word, because he perceives it by his senses. Ask him why he thinks an orange tree not to be there, and he shall tell you, because he does not perceive it. What he perceives by sense, that he terms a real being, and says it 'is' or 'exists'; but that which is not perceivable, the same, he says, has no being (234).

The most noteworthy thing about this exchange is that Philonous never disputes Hylas's claim that the gardener does not believe EIP. Instead, he appeals

8. Here I again agree with Holtzman 2013 against Pappas 1982, 2000. 
to the gardener's practice: first to his epistemic practice and then to his linguistic practice. $^{9}$

The gardener's practice of immediately and unreflectively attributing existence to the objects of the senses was an explicit target of Cartesian attack. In order that the mind may be led away from the senses, the Cartesians held, we must learn that the senses do not give us knowledge of bodies and therefore resist the temptation to assume (without further support) that whatever we perceive by our senses really exists (CSM, 2:12-23; Malebranche [1688] 1997, $8-12)$.

According to Berkeley, this attack on the gardener is a mess of philosophical confusions. Untangling this collection of philosophical errors about mind, language, and knowledge will show that there is no 'speculative' standpoint outside "the common actions of life" (DHP, 246) from which the philosophers can launch their attacks.

The first and most foundational error of the philosophers, according to Berkeley, is the view "that language has no other end but the communicating our ideas, and that every significant name stands for an idea" (PHK, Intro §19). This view about language gives rise to the theory of abstract ideas. The theory of abstract ideas is in turn responsible for the illusion of meaningfulness in speculation divorced from practice. A prime example of such speculation is the attempt to construct "an abstract idea of existence exclusive of perceiving and being perceived" (CGB, 319), an idea Berkeley describes as "the most abstract and incomprehensible of all other" (PHK, §17). The supposition that there is such an idea, and that this idea is the meaning of the words 'is' and 'exists', is responsible for calling the gardener's linguistic and epistemic practice into question. If there is no such idea - if we cannot consider the cherry tree's existence in a way that is divorced from our practice of interacting with the objects of sensory perception - then, Berkeley holds, the ordinary practice of existence ascription is immune from philosophical criticism.

To defend this line of argument, Berkeley develops a radical account of mind, language, and knowledge. Berkeley holds that "the true end of speech ... is ... something of an active, operative nature, tending to a conceived good" (Alc, $\S 7.17)$. In order to understand a bit of language, we must "make sense of our daily practice" ( $\$ 7.8)$ of employing it in pursuit of this end by identifying the particular goods at which it aims and the rules agents follow in this pursuit.

It is within the context of this theory that Berkeley is able to employ EIP in his defense of the gardener against the philosophers' attacks. EIP is not a proposition the gardener believes. It is a rule the gardener follows. In fact, EIP appears in the gardener passage in two closely related versions, one epistemic and one linguistic. The epistemic version of the EIP rule authorizes one to believe that an object exists whenever one perceives that object. The linguistic version authorizes one to apply the predicate 'exists' to any object that is presently perceived (or, equivalently, to any object to which the predicate

9. It is on precisely this basis that Pappas criticizes this passage as 'unconvincing' (Pappas $2000,216)$. 
'perceived' applies). In Berkeley's view, the facts of English usage demonstrate the validity of linguistic EIP and, by disquotation, linguistic EIP validates epistemic EIP. None of this requires the gardener to have any explicit beliefs about linguistic or epistemic rules. All that matters is that the gardener applies the predicate 'exists' to presently perceived cherry trees, and not to unperceivable orange trees, and this practice is authorized by the rules of English usage.

This interpretation of Berkeley will likely strike many readers as wildly anachronistic. The focus on rule-following, the 'externalist' denial that knowledge about the rule is required, and the employment of facts about linguistic usage to deflate metaphysical debates may all seem more at home in the middle of the 20th century than at the beginning of the $18 \mathrm{th}$.

The following sections will provide a textual and contextual defense of the interpretation I have proposed. In order to answer the charge of anachronism, I begin with a discussion of theories of knowledge in the 17th century background to Berkeley. Special attention is paid to the role of rules and of abstract ideas in Cartesian and Lockean epistemology. Then I show how Berkeley's novel theory of mental and linguistic representation radically transforms these theories and thereby validates the gardener's knowledge.

\section{Rules and Knowledge in Berkeley's Predecessors}

To place Berkeley's views on the gardener's knowledge in their historical context, we here examine three key texts in 17th century epistemology: Descartes's Rules for the Direction of the Mind (c. 1628), ${ }^{10}$ the (Cartesian) Port-Royal Logic (1662), and Locke's Essay (1689).

According to the Rules, "there are no paths to certain knowledge of the truth accessible to men save manifest intuition and necessary demonstration" (CSM, 1:48). ${ }^{11}$ 'Intuition' is defined as "the indubitable conception of a clear and attentive mind" (1:14). The Latin word 'intuitio' suggests a visual metaphor, and Descartes develops this metaphor explicitly: intuition is the ability of the intellect to 'just see' that a proposition is true (1:33). Demonstration consists in the stringing together of several intuited propositions in order to arrive at knowledge of a proposition that is not intuited $(1: 37-39,48)$.

Descartes's Scholastic predecessors had focused their attention on identifying the valid syllogistic forms in the belief that reasoning from first principles in explicit accordance with these forms was the way to gain knowledge (scientia).

\footnotetext{
10. Descartes never finished the Rules, and the Latin text was not published until 1701 (a Dutch translation appeared in 1684), but it was widely circulated in manuscript in the 17th century and was read by Antoine Arnauld, the primary author of the Port-Royal Logic (see Murdoch's preface in CSM, 1:7). The text of the Rules would also have been available to Berkeley, though it is unclear whether he had read it. The relationship of the Rules to Descartes's later works is disputed. See, e.g., Garber 1988; Florka 2004.

11. Descartes's Latin term is 'deductio,' which Murdoch translates 'deduction'. I use 'demonstration' since this is the term for the analogous concept in Locke and Berkeley.
} 
In Descartes's view, this approach rests on a mistake regarding the source of error: "In fact none of the errors to which men ... are liable is ever due to faulty inference; they are due only to the fact that men take for granted certain poorly understood observations, or lay down rash and groundless judgments" (CSM, $1: 12)$.

In the Rules, Descartes argues that, instead of attempting to force our reasoning into syllogistic form, we should begin by attending carefully to very simple propositions. If we do this, Descartes believes, we will be able to see, in a way completely immune from doubt, that some of them are true. These simple propositions can serve as first principles. To learn more complex propositions, we chain these together, making sure that the correctness of each link in the chain is intuited. This is demonstration (1:14-15).

Descartes gives the following list of intuited propositions: "everyone can mentally intuit that he exists, that he is thinking, that a triangle is bounded by just three lines, and a sphere by a single surface, and the like" (1:14). ${ }^{12}$ None of these propositions has the explicit form of an inference rule, nor is any of them a logical principle as abstract as the Law of Non-Contradiction or the principle that the whole is greater than the part. Furthermore, not all of them are necessary truths: it is contingent that I exist and that I am thinking. Yet all of these, for Descartes, are eligible to serve as first principles.

A central aspect of Descartes's epistemology is its devaluing of explicit knowledge of inference rules and of highly abstract propositions. Instead, we are told to focus on particular simple propositions in order to gain intuitive knowledge. This is closely connected with Descartes's view that all human beings have the same basic intellectual endowment so that, as he puts it in the Discourse on Method, "the diversity of our opinions does not arise because some of us are more reasonable [i.e., better at reasoning] than others but solely because we direct our thoughts along different paths and do not attend to the same things" (1:111). Reasoning is not a specialized technique to be taught and learned through esoteric rules; it is just a matter of careful attention.

The same approach animates the Port-Royal Logic. The authors describe the scope, aims, and method of their work as follows:

this art [of thinking, i.e., logic] does not consist in finding the means to perform [mental] operations, since nature alone furnishes them in giving us reason, but in reflecting on what nature makes us do, which serves three purposes.

The first is to assure us that we are using reason well, since

12. Frederick Van de Pitte (1988) argues that the objects of intuition are not strictly speaking propositional. Yet it is clear from the text - and Van de Pitte does not dispute this - that intuition somehow leads to infallibly certain judgments, and thereby makes possible the individual steps in demonstration. If Van de Pitte is correct that, in defining intuition as "the conception of a clear and attentive mind" (CSM, 1:14, emphasis added) Descartes means to suggest that intuition is merely the having of clear and distinct ideas and that the judgments are subsequently 'read off' of these ideas, this would bring Descartes closer to the views of Port-Royal and Locke, discussed below, on which intuitive knowledge comes from the comparison of ideas. 
thinking about the rule makes us pay new attention to it.

The second is to reveal and explain more easily the errors or defects that can occur in mental operations. For we frequently discover by the natural light of reason alone that some reasoning is fallacious without, however, knowing why it is so...

The third purpose is to make us better acquainted with the nature of the mind by reflecting on its actions (Arnauld and Nicole [1662] 1996, 23).

Arnauld and Nicole go beyond Descartes in developing a theory of judgment which provides an account of intuition. They write, "After conceiving things by our ideas, we compare these ideas and, finding that some belong together and others do not, we unite or separate them. This is called affirming or denying, and in general judging" (82). To 'just see' that a (simple, affirmative) proposition is true, one holds the subject idea and the predicate idea before the mind, compares them, and finds that they 'belong together'. A proposition of this sort is indubitable and therefore appropriately taken as an axiom. All other propositions must be demonstrated by exhibiting the connection of the subject to the predicate through a connected chain of ideas. Each link in such a chain must be intuited (246-249).

The third part of the Logic deals with reasoning. Its preface begins as follows:

The part we now have to discuss, which includes the rules of reasoning, is considered the most important part of logic ... But there is reason to doubt whether it is as useful as is generally supposed. The majority of people's errors ... depend more on reasoning based on false principles, than from reasoning incorrectly from their principles ... And those who could not recognize a fallacy by the light of reason alone would usually not be able to understand the rules behind it, much less to apply them (135).

Nevertheless, the authors go on to discuss the rules of reasoning since "when these rules are viewed as speculative truths, they are always useful for exercising the mind" (135). Accordingly, the treatment of the rules of reasoning must be understood as aimed primarily at the Logic's third purpose, "mak[ing] us better acquainted with the nature of the mind by reflecting on its actions" (23).

According to Arnauld and Nicole, explicitly formulated syllogistic rules do not serve to improve our reasoning, but only to improve our theoretical understanding of "what nature makes us do" (23). We would not be able to understand the abstract statement of a rule like modus ponens and recognize its validity unless we already knew how to follow that rule. ${ }^{13}$

Despite Locke's empiricism and his anti-Cartesian polemics, his theory of judgment, intuition, and demonstration follows Port-Royal quite closely. ${ }^{14}$ Locke

13. For a more detailed treatment of the Port-Royalists' philosophy and pedagogy of logic, see Finocchiaro 1997.

14. Whether Locke had read Descartes's Rules at the time he developed his epistemology has been questioned (O'Kelley 1971), but it is indisputable that Locke was familiar with the Port- 
defines knowledge as "the perception of the connexion and agreement, or disagreement and repugnancy of any of our Ideas" (EHU, §4.1.2). Knowledge is intuitive when "the Mind perceives the Agreement or Disagreement of two Ideas immediately by themselves, without the intervention of any other" (§4.2.1) and demonstrative when the mind "by the Intervention of other Ideas ... discover[s] the Agreement or Disagreement" (§4.2.2). Demonstrative knowledge involves a chain of reasoning in which the validity of each step is intuitive ( $§ 4.2 .7)$.

Locke similarly follows Descartes and Port-Royal in dismissing the importance of the highly abstract principles known as 'maxims' or 'axioms' and of the syllogistic forms (Jolley 1999, 170-175; Newman 2007a, 326-327). He argues specifically that these are not the first truths we know, and that our knowledge of other truths does not depend on them (EHU, $\S \S 4.7 .8-10)$. Thus, for instance, "a Child certainly knows, that a stranger is not its Mother; that its Suckingbottle is not the Rod, long before he knows, that 'tis impossible for the same thing to be, and not to be" (§4.7.9). ${ }^{15}$ Echoing Port-Royal, Locke concludes his discussion of maxims as follows:

where our Ideas are determined in our Minds ... there is little need, or no use at all of these Maxims, to prove the Agreement, or Disagreement of any of them. ... he that needs any proof to make him certain ... that Two are equal to Two, will also have need of a proof to make him admit that What is, is (§4.7.19).

Intuitive knowledge, then, occurs when we can 'just see' that the subject idea and the predicate idea 'belong together'. This is easier in cases of simple, particular ideas. As a result, these are truly the first principles. The particular instances of intuitive knowledge do fall under general rules like what is, is and the whole is greater than the part, but knowledge of the particular instances does not depend on knowledge of the general rule.

Now consider the proposition this cherry tree exists. This is a simple affirmative proposition; accordingly, to know it we would need to perceive an agreement between the subject idea (i.e., the particular idea of this cherry tree) and the predicate idea (i.e., the abstract general idea existence). For both the Cartesians and Locke, intuition (and knowledge generally) is supposed to be psychologically irresistible. ${ }^{16}$ Descartes's skeptical arguments were meant to show that it is possible to doubt the existence of the cherry tree even at the

Royal Logic. On the influence of Port-Royal on Locke's account of judgment in particular, see Mattern (1978) 1998; Ott 2002; Schaar 2008; Marui 2014. For a comparison of Locke's views on intuition and demonstration with the views found in the Rules, see Jolley 1999, 170-175.

15. This section was very familiar to Berkeley - it concludes with the notorious 'inconsistent triangle' passage which Berkeley described as his "killing blow" to the theory of abstract ideas (N, §687; see PHK, Intro $§ 13)$.

16. Descartes and Malebranche hold that we are sometimes able to assent and able to withhold judgment, but if we assent in such cases our assent will never amount to knowledge (CSM, 1:194, 2:41-43; Malebranche [1674-1675] 1997, 8-11; for discussion, see Scott 2008). The view of the Port-Royalists on this matter is unclear (see Buroker 1996). Locke holds that all assent is involuntary, though we can control our assent indirectly by directing our attention to different considerations (EHU, ch. 4.13, §4.20.16; Locke 1823, 6:10-11, 39-40; for discussion see Passmore [1980] 1998; Jolley 1999, 191-193; Owen 2007, 431-433). 
instant we are seeing it. Accordingly, not only is there no intuited connection between this cherry tree and existence, there is similarly no intuited connection between perceived cherry tree and existence. It follows that we cannot have intuitive knowledge of the existence of the cherry tree.

\section{Rules and Knowledge in Berkeley}

On my reading of Berkeley, EIP has the same status as other 'maxims' such as what is, is: it is a highly general principle under which myriad instances of intuitive knowledge fall. Knowledge of the instances is prior to and independent of knowledge of the general rule. Thus the gardener's knowledge that his (perceived) cherry tree exists does not depend on prior knowledge of (or belief in) EIP.

However, Berkeley's rejection of abstract ideas (PHK, Intro $\S \S 6-21)$ significantly complicates the picture. For Port-Royal and Locke, to judge that the cherry tree exists would be to join the idea of this cherry tree and the idea of existence in a mental proposition. ${ }^{17}$ But Berkeley regards "[t]he general idea of being" (existence) as "the most abstract and incomprehensible of all other" (§17). In Berkeley's view, the mental proposition which, according to PortRoyal and Locke, is supposed to be signified by the sentence 'this cherry tree exists' is impossible. Thus Berkeley cannot mean by 'intuitive knowledge' what his predecessors did.

This is where language enters the picture: Berkeley combines a radical nominalism according to which all generality arises from conventional signification with a use theory of signification according to which a word or other idea gets to be significant (meaningful) when it is used according to a rule to accomplish a practical purpose. ${ }^{18}$ These elements together lead Berkeley to a formalist theory of inference, so that rules of linguistic usage effectively replace the epistemic rules of Berkeley's predecessors. In this way, epistemic EIP is actually identified with linguistic EIP. Or so I shall argue.

In introducing his radical nominalism, Berkeley quotes Locke's query, "since all things that exist are only particulars, how come we by general Terms ...?" (EHU, §3.3.6). Berkeley responds as follows: "[Locke's] answer is, "Words become general by being made the signs of general ideas.' But it seems that a word becomes general by being made the sign, not of an abstract general idea, but of several particular ideas" (PHK, Intro §11). Neither words nor ideas, in Berkeley's view, are in their own nature general. They become general by means of conventional signification:

17. I follow Buroker 1993, 1996; 2014, §3.1; Owen 2007, §2; and Marui 2014 (against Ott 2002) in taking this 'joining of ideas' to have assertive force, both for Locke and for Port-Royal. Schaar 2008 takes 'joining of ideas' to have assertive force for Port-Royal but not Locke.

18. It has long been recognized that in Alciphron VII Berkeley developed a use theory of language which anticipated, in certain respects, the later Wittgenstein (Flew [1974] 1993). More recently, John Russell Roberts has argued that this proto-Wittgensteinian theory is already at work in the Introduction to the Principles (Roberts 2007, ch. 2). 
By observing how ideas become general, we may the better judge how words are made so ... an idea, which considered in it self is particular, becomes general by being made to represent or stand for all other particular ideas of the same sort ... as the [general idea of a line] owes its generality, not to its being the sign of an abstract or general line, but of all particular right lines that may possibly exist, so the [word 'line'] must be thought to derive its generality from the same cause, namely, the various particular lines which it indifferently denotes (PHK, Intro §12).

That this conclusion - that generality derives from conventional significationis meant absolutely universally becomes explicit in the 1732 work Alciphron: "all sciences, so far as they are universal and demonstrable by human reason, will be found conversant about signs as their immediate object" (Alc, §7.16).

Berkeley's radical nominalism, however, faces a serious objection: "it is a received opinion that language has no other end but the communicating our ideas, and that every significant name stands for an idea" (PHK, Intro §19). According to this 'received opinion' - which is clearly endorsed, for instance, by Port-Royal and Locke each name is supposed to stand for one idea which is the meaning of that name. Any deviation from this norm is classified as an 'imperfection' or 'abuse' of language (Arnauld and Nicole [1662] 1996, 58-66; EHU, $\S 3.9 .4-5,3.10 .2-3,5,28$; cf. MI, 331 ; PHK, Intro §18).

In denying that there are intrinsically general ideas, Berkeley is denying that there is, or could be, any such thing as the (one and only) meaning of a general word like 'line'. In Alciphron, Berkeley goes further:

the true end of speech ... may sometimes be obtained, not only although the ideas marked are not offered to the mind, but even although there should be no possibility of offering or exhibiting any such idea to the mind: for instance, the algebraic mark, which denotes the root of a negative square, has its use in logistic operations, although it be impossible to form an idea of any such quantity (Alc, $\S 7.17)$.

In fact, the ultimate conclusion at which Berkeley is driving in the Introduction to the Principles and in Alciphron VII is that there are no such things as meanings. ${ }^{19}$ Thus Berkeley's contemporary Peter Browne was perfectly correct to characterize Berkeley as holding that "Words may be Significant, tho' they signify Nothing" (Browne 1733, 534).

The title character of Alciphron finds this view baffling: "this is the opinion of all thinking men who are agreed, the only use of words is to suggest ideas. And indeed what other use can we assign them?" (Alc, §7.7). Berkeley's spokesman Euphranor responds: "Be the use of words or names what it will, I can never think it is to do things impossible [i.e., to suggest abstract ideas]. Let us then inquire what it is? and see if we can make sense of our daily practice"

19. I explain and defend this claim at length in Pearce 2017, ch. 1. 
(§7.8). Berkeley's approach to understanding language - employed as early as the Manuscript Introduction (1708), but articulated only in Alciphron-is first to inquire into the ends at which a word or discourse aims, and then to inquire into the rules speakers follow in order to achieve those aims. "[T] he true end of speech ... is not merely, or principally, or always the imparting or acquiring of ideas, but rather something of an active operative nature, tending to a conceived good" (Alc, §7.17; cf. PHK, Intro §20). Words don't get to be meaningful by having meanings. Words get to be meaningful by being used in 'daily practice' according to rules which enable us to achieve a 'conceived good' (see Pearce 2017, chs. 2-3).

Since words don't have meanings, neither do sentences. In the Manuscript Introduction, Berkeley considers the example sentence 'Melampus is an animal'. In this sentence, Berkeley argues, 'animal' cannot signify the idea of Melampus or any other particular animal, since 'Melampus is Melampus' is a tautology and 'Melampus is Fido' is a falsehood, but 'Melampus is an animal' is neither a tautology nor a falsehood (MI, $\S 35) .{ }^{20}$ Since there is no abstract idea for 'animal' to signify and 'animal' (as used in this sentence) can't signify a particular animal idea, the proposition cannot be constructed by putting two ideas together in the way Port-Royal and Locke suppose. Instead, "All that I intend to signify thereby [is] only this. That the particular thing I call Melampus has a right to be called by the Name Animal" ( $\S 34$, bracketed text omitted). For Berkeley, the proposition - the fundamental truth-bearer - just is the sentence. In the simplest cases, such as 'Melampus is an animal', the sentence just applies two labels to the same idea. If the labels are applied correctly, in obedience to the rules, the sentence is true.

In his mature theory, Berkeley gets well beyond this toy example. Even in the Principles Berkeley does not see this kind of signification or classification as the "chief and only end of language" (PHK, Intro §20). Yet the general point stands: a sentence is true when it is being used in obedience to the rules as part of a successful scheme for achieving our practical ends. ${ }^{21}$

Let us return to the topic of knowledge. Berkeley adopts from his predecessors the distinction between intuitive and demonstrative knowledge. He does not give an explicit definition of intuitive knowledge, though he does associate it with immediacy (DHP, 231). Presumably, then, the structural relationship between these two types of knowledge is the same for Berkeley as for his predecessors: the intuitive propositions are known immediately, and demonstration proceeds by chaining propositions together in such a way that each step is intu-

20. Earlier versions of this line of argument can be found in several places in the notebooks. For discussion see Holtzman 2013, 10-13.

21. Berkeley's actual view is somewhat more complicated, since he recognizes the possibility of bad linguistic rules that lead to contradictions, harmful practical advice, and so forth (see, e.g., PHK, §52; TVV, §35; Siris, §296). In these cases, as I argue in Pearce 2017, 157-171, the resulting assertion will be partly true and partly false. Thus a more precise formulation would be: a sentence is true to the degree that it is being used in obedience to the rules as part of a successful scheme for achieving our practical ends. Our actual language is an imperfect tool for achieving our ends and our assertions therefore do not exhibit maximal truth but this, in Berkeley's view, does not endanger ordinary knowledge claims. 
ited. If this is right, then we can make some headway by considering Berkeley's remarks about demonstration.

Regarding mathematical reasoning, Berkeley writes,

the one who understands the notation of numbers, by means thereof is able ...to perform with ease and dispatch several arithmetical operations, by the help of general rules ... the science of arithmetic, in its rise, operations, rules, and theorems, is altogether conversant about the artificial use of signs, names, and characters (Alc, §7.15).

In the Principles, this procedure is described as 'computing in signs' (PHK, $\S 121)$.

As a number of scholars have pointed out, ${ }^{22}$ in these texts Berkeley endorses a formalist theory of mathematics: mathematical reasoning just is the manipulation of symbols according to conventional ('artificial') rules. What previous scholars have not emphasized is that Berkeley frequently makes use of mathematical analogies to explain his theory of language (see, e.g., PHK, Intro $\S 19$; Alc, §7.8). In Alciphron, he justifies this practice by the remark that "modern algebra [is] in fact a more short, apposite, and artificial sort of language" (Alc, $\S 7.17)$. This supports the conclusion that Berkeley's formalism is meant as a general theory of inference, and not only a philosophy of mathematics.

If the analogy to earlier theories of intuitive and demonstrative knowledge is to be preserved, then each step in a chain of inferences must be regarded as intuitive. On Berkeley's account, this will have the result that a proposition (sentence) is known intuitively when it results immediately from the application of the rule. Thus, for instance, if I have the idea of Melampus before my mind and I can 'just see' that, by the rules for the use of 'animal,' "Melampus has a right to be called by the Name Animal" (MI, §34), then I have intuitive knowledge that Melampus is an animal. The same will apply to any other casewhether or not it involves classification of ideas - in which I can 'just see' that the rules authorize the assertion. ${ }^{23}$ Because among the linguistic rules are rules for moving from one sentence to another, I can chain together applications of rules to produce demonstrative knowledge. This is what Berkeley calls 'computing in signs' (PHK, §121).

Berkeley holds that all general thought requires the use of signs, and that the use of signs proceeds by conventional rules. These rules are themselves general. Thus to hold that the following of a rule required explicit, articulable knowledge of that rule would involve Berkeley in regress or circularity. ${ }^{24}$ However, as we have seen, Berkeley's predecessors had already rejected this assumption. Berkeley, speaking specifically about linguistic rules, rejects it as well: "Two ways there are of learning a language, either by rule or by practice; a man may

22. See, e.g., Baum 1972; Brook 1973, 152-155; Jesseph 1993, 106-114; Schwartz 2010.

23. Again, complexities are introduced by Berkeley's recognition of degrees of truth or falsehood. (See above, note 21.)

24. This difficulty belongs to a well-known family of circularity and/or regress problems in the philosophy of language and logic. See, e.g., Quine (1935) 1976, 103-106; (1954) 1976, 115; Wittgenstein 1953, §§1.84-87. 
well read in [a language] without understanding the grammar of it, or being able to say by what rule a thing is so or so" (PHK, $\S 108$ [1710 ed.]). Berkeley's predecessors held that we recognize and produce good reasoning in particular instances first, and only later gain an explicit grasp of the general rules common to all good reasoning. In the same way, according to Berkeley, we learn to speak and understand the language first, and this includes learning to perform the inferences it authorizes. It is only later that we reflect on our practice and thereby come to an explicit grasp of the general rules of our language. When, by following a rule we have mastered, we recognize the correctness of the application of a sign, we have immediate, or intuitive, knowledge.

All reasoning, for Berkeley, is computing in signs. This computation proceeds according to rules which are part of the conventions for the use of the signs (words) involved. If the interpretation developed above is correct, Berkeley cannot hold (as most of his predecessors held) that these rules are mere reflections of prior structures of thought and reasoning, for on Berkeley's view the conventional rules for the use of signs make general thought and reasoning possible. Instead, Berkeley must hold that the rules of reasoning, like all the rules of language, are "framed by the vulgar, merely for conveniency and dispatch in the common actions of life" (DHP, 246). ${ }^{25}$

The rules of reasoning just are (some of) the rules of language. In particular, epistemic EIP just is linguistic EIP. If this is in fact the correct rule for the use of 'exists,' and if the gardener is following it in forming his judgment that the cherry tree exists, then the gardener has intuitive knowledge of the cherry tree's existence, despite the fact that he has never explicitly considered the EIP rule, and might well reject it if he did consider it.

\section{How the Gardener Knows his Cherry Tree}

The final task Berkeley must perform in order to defend the gardener's knowledge of his cherry tree is to show that EIP is one of the rules for the use of 'exists' in English. In Berkeley's view, "Common custom is the standard of propriety

25. I claimed above (note 2) that my thesis was consistent with Holtzman's general line of interpretation which states that common sense, for Berkeley, is the proper use of one's faculties. Within that framework, my point could be stated as follows: in Berkeley's view, we do not have a faculty of reason with certain precise rules of reasoning 'built in'. Rather, our faculty of understanding - that is, of having ideas (PHK, §27) - is highly malleable, moving from one idea to another based on conventional or habitual rules (see Pearce 2017, ch. 4). Since "the human mind ... [was] designed, not for the bare intuition of ideas, but for action or operation about them, and pursuing her own happiness therein" (Alc, §7.14), any employment of this faculty is 'proper' to the extent that it is conducive to success in "the common actions of life." That the rules of ordinary language are so conducive- that they enable the gardeners of the world to know when to water, when to prune, when to fertilize, and so forth - is beyond dispute. As we will see in the next section, the materialist's revision of the rules for the application of 'exist' to sensible objects represents a perversion of this faculty precisely insofar as it attempts to lead the mind away from the senses and hence away from the objects of practical concern. 
in language" (DHP, 216) ${ }^{26}$ and "words ... were framed by the vulgar, merely for conveniency and dispatch in the common actions of life, without regard for speculation" (246). Hence the relevance of the gardener's linguistic practice: the common custom of the vulgar in the common actions of life is the source of linguistic norms.

Berkeley frequently says that a proper understanding of the word 'exists' is central to his project. For instance, he writes in his notebooks, "tis on the Discovering of the nature \& meaning \& import of Existence that I chiefly insist" (N, §491). Note, though, that Berkeley calls this a 'discovery,' and later in the same entry he goes on to write: "This I think wholly new. I am sure 'tis new to me." Given Berkeley's theory of language, this 'discovery' must involve coming, by reflection on our practices, to explicit meta-linguistic awareness of the rule we follow. This is supported by other texts. Thus a later notebook entry reads: "I am persuaded would Men but examine $\mathrm{w}^{\mathrm{t}}$ they mean by the Word Existence they wou'd agree with me" ( $\$ 604)$, and at the beginning of the Principles: "an intuitive knowledge may be obtained of [immaterialism] by any one that shall attend to what is meant by the term 'exist' when applied to sensible things" (PHK, §3). ${ }^{27}$ This 'examination' or 'attention' is meant to reveal to us what we had meant by 'exist' all along. ${ }^{28}$

The question, then, with which we are faced is: how is the predicate 'exists' applied to sensible objects by the vulgar in the common actions of life? What conventional norms govern this practice, and what ends does the practice aim to achieve?

This brings us back to the case of the gardener: "What he perceives by sense, that he terms a real being, and says it 'is' or 'exists'; but that which is not perceivable, the same, he says, has no being" (DHP, 234). The philosophers (especially the Cartesians) had sought to cast doubt on the legitimacy of this practice by arguing that presently perceived objects might fail to exist. Berkeley's question regarding this skeptical discourse is, what is meant by 'exist' here? The use of the word has come totally unmoored from any basis in "our daily practice" (Alc, §7.8) and from "the true end of speech ... [which is] something of an active, operative nature, tending to a conceived good" ( $\$ 7.17)$.

The gardeners of the world who are appropriately immersed in the practice of language with practical ends in view do not "distinguish [the] real nature [of bodies] from that which falls under our senses" (DHP, 167) as the Cartesians and Locke would have us do. Philonous explains:

To be plain, it is my opinion that the real things are those very

26. Hylas is the speaker here, but this is a concession he makes at Philonous's prompting. For exposition of this remark, see Pearce 2017, 76-78.

27. The qualification 'when applied to sensible things' is important, for 'exists' has a totally different use in its application to spirits. See Pappas 2002; Bettcher 2007; Roberts 2007, ch. 1; Pearce 2017, 135-138.

28. This does not make EIP what Pappas calls a 'reflective common sense proposition' for it is not the case that "a typical common sense person would believe [it] upon some unbiased reflection on the matter" (Pappas 2000, 214). It takes an atypical common sense person (namely, Berkeley) to direct us to the sort of reflection necessary to see the correctness of EIP. 
things I see and feel, and perceive by my senses. These I know, and finding they answer all the necessities and purposes of life, have no reason to be solicitous about any other unknown beings. A piece of sensible bread, for instance, would stay my stomach better than ten thousand times as much of that insensible, unintelligible, real bread you speak of ... You indeed, who by 'snow' and 'fire' mean certain external, unperceived, unperceiving substances, are in the right to deny whiteness or heat to be affections inherent in them. But I, who understand by those words the things I see and feel, am obliged to think like other folks. And as I am no sceptic with regard to the nature of things, so neither am I as to their existence. That a thing should be really perceived by my senses, and at the same time not really exist, is to me a plain contradiction, since I cannot prescind or abstract, even in thought, the existence of a sensible thing from its being perceived (DHP, 229-230).

It is because Philonous has kept his focus on those things that "answer all the necessities and purposes of life" that he is "obliged to think like other folks," i.e., like the gardener.

The gardener, like other uncorrupted English speakers, immediately, intuitively applies the word 'exists' to perceived cherry trees. Insofar as the application of the word follows immediately on the cherry tree's being perceived, without any intermediate chain of reasoning, this application must be immediately authorized by the rules of language. The gardener has mastered these rules and follows them in his use of 'exists,' thereby gaining intuitive knowledge that the cherry tree exists.

Berkeley's 'discovery,' gained by reflection on this practice, is that the esse of a sensible object just is its percipi or, in meta-linguistic terms, that the rules for the proper use of the terms 'exists' and 'is perceived' ensure that every object that has a right to the predicate 'is perceived' likewise has a right to the predicate 'exists'. This is the case Berkeley is making in more detail in PHK, $§ 3$ :

The table I write on, I say, exists, that is, I see and feel it; and if I were out of my study I should say it existed, meaning thereby that if I was in my study I might perceive it, or that some other spirit actually does perceive it. There was an odour, that is, it was smelled; there was a sound, that is to say, it was heard; a colour or figure, and it was perceived by sight or touch. This is all that I can understand by these and the like expressions. For as to what is said of the absolute existence of things without any relation to their being perceived, that seems perfectly unintelligible.

Note that Berkeley here gives a very simple semantics for 'exists' as applied to odors, sounds, colors, and figures, but a much more complicated semantics for 'exists' as applied to tables. Some commentators have seen an inconsistency here (e.g., Tipton 1974, 100-101). However, this inconsistency is easily resolved if Berkeley distinguishes bodies from ideas and attributes different existence 
conditions to them. ${ }^{29}$ In fact, just such a distinction is apparently drawn in PHK, $§ 1$ :

as several of these [sensible ideas] are observed to accompany each other, they come to be marked by one name, and so reputed as one thing. Thus, for example, a certain colour, taste, smell, figure and consistence having been observed to go together, are accounted one distinct thing, signified by the name 'apple'.

The ideas, according to Berkeley, "come to be marked by one name, and so [i.e., by being given a name] reputed as one thing." The function of the name "apple', whereby it contributes to the practical purposes of language, is to organize sensed ideas: to unite them into things (apples). As part of this organizational apparatus, we sometimes say 'the apple exists' even when no apple ideas are perceived (and hence no such ideas exist). Nevertheless, if the purpose of words like 'apple' is to organize sensed ideas, then the attribution to apples of "absolute existence ... without any relation to being perceived" will indeed be "unintelligible" ( $\S 3$, emphasis added), since that utterance will lack any connection to the practical ends at which 'apple' talk aims. ${ }^{30}$

As Berkeley sees things, to speak of "the absolute existence of [sensible] things without any relation to their being perceived" is to divorce sensible object talk completely from the domain of the practical and hence from the conditions that make it meaningful. To recognize this fact is to expose the philosophical doubts of Locke and the Cartesians as linguistic confusions. Clearing up these confusions enables us to see that there is nothing defective about the gardener's linguistic and epistemic practice and, ultimately, to return to that practice ourselves. It is in this way that, by Berkeley's philosophy, "men [are] reduced from paradoxes to common sense" (DHP, 168). ${ }^{31}$

\section{Abbreviations}

Alc Berkeley, George. (1732) 2010. Alciphron: or, the Minute Philosopher. In Berkeley's Alciphron: English Text and Essays in Interpretation, edited by Laurent Jaffro, Genevive Brykman, and Claire Schwartz, 17-274. Hildesheim: Georg Olms Verlag.

CGB Hight, Marc A., ed. 2013. The Correspondence of George Berkeley. Cambridge: Cambridge University Press.

29. In finding such a distinction in the opening sections of the Principles, I follow Muehlmann 1992, 13-15 et passim.

30. For a detailed exposition and defense of this interpretation of Berkeley's theory of bodies, see Pearce 2017, ch. 6.

31. A previous version of this paper was presented at the conference commemorating the 300th anniversary of the Three Dialogues at the Jagiellonian University, Krakow, Poland where I had many helpful conversations with conference participants, especially George Pappas and Martha Brandt Bolton. I also thank Samuel Rickless, Sandra Visser, Mark Schwehn, Seth Bordner, and two anonymous referees for helpful comments on previous drafts. 
CSM Cottingham, John, Robert Stoothoff, Dugald Murdoch, and Anthony Kenny, trans. 1984-1991. The Philosophical Writings of Descartes. 3 vols. Cambridge: Cambridge University Press.

DHP Berkeley, George. (1713) 2008. Three Dialogues Between Hylas and Philonous . In Clarke 2008, 151-242.

EHU Locke, John. (1690) 1975. An Essay Concerning Human Understanding. Edited by Peter H. Nidditch. Oxford: Oxford University Press.

MI Berkeley, George. 1987. George Berkeley's Manuscript Introduction: An Editio Diplomatica. Edited by Bertil Belfrage. Oxford: Doxa.

N Berkeley, George. 1989. Philosophical Commentaries. Edited by George Hasson Thomas. The Philosophy of George Berkeley. Ohio: Garland.

PHK Berkeley, George. (1710) 2008. A Treatise Concerning the Principles of Human Knowledge. In Clarke 2008, 67-149.

Siris Berkeley, George. (1744) 1948-1957. Siris: A Chain of Philosophical Reflexions and Inquiries Concerning the Virtues of Tar-water, and divers other Subjects connected together and arising One from Another. In The Works of George Berkeley, Bishop of Cloyne, edited by A. A. Luce and T. E. Jessop, 5:31-164. 9 vols. London: Thomas Nelson and Sons.

TVV Berkeley, George. (1733) 1998. The Theory of Vision, or Visual Language, Shewing The Immediate Presence and Providence of a Deity, Vindicated and Explained. In Philosophical Works Including the Works on Vision, edited by Michael Ayers, 277-304. London: J. M. Dent.

\section{References}

Arnauld, Antoine, and Pierre Nicole. (1662) 1996. Logic or the Art of Thinking: Containing besides common rules, several new observations appropriate for forming judgments. Edited and translated by Jill Vance Buroker. Cambridge Texts in the History of Philosophy. Cambridge: Cambridge University Press.

Atherton, Margaret. 1991. 'Corpuscles, Mechanism, and Essentialism in Berkeley and Locke.' Journal of the History of Philosophy 29 (1): 47-67.

Baum, Robert J. 1972. 'The Instrumentalist and Formalist Elements in Berkeley's Philosophy of Mathematics.' Studies in the History and Philosophy of Science Part A 3:119-134.

Berman, David. 2010. 'The Distrustful Philosopher: Berkeley Between the Devils and the Deep Blue Sea of Faith.' In Parigi 2010, 141-157.

Bettcher, Talia Mae. 2007. Berkeley's Philosophy of Spirit: Consciousness, Ontology, and the Elusive Subject. London: Continuum.

Bordner, S. Seth. 2011. 'Berkeley's "Defense" of "Commonsense."' Journal of the History of Philosophy 49 (3): 315-338. 
Boyle, Robert. (1666) 1991. The Origin of Forms and Qualities According to the Corpuscular Philosophy. In Selected Philosophical Papers of Robert Boyle, edited by M. A. Stewart, 1-96. Indianapolis: Hackett.

Brook, Richard J. 1973. Berkeley's Philosophy of Science. The Hague: Martinus Nijhoff.

Browne, Peter. 1733. Things Divine and Supernatural Conceived by Analogy with Things Natural and Human. London: William Innys / Richard Manby.

Buroker, Jill Vance. 1993. 'The Port-Royal Semantics of Terms.' Synthese 96 (3): 455-475.

. 1996. 'Arnauld on Judging and the Will.' In Interpreting Arnauld, edited by Elmar J. Kremer, 3-12. Toronto: University of Toronto Press.

. 2014. 'Port Royal Logic.' In The Stanford Encyclopedia of Philosophy, Fall 2014 Edition, edited by Edward N. Zalta. http://plato. stanford. edu/archives/fall2014/entries/port-royal-logic/.

Chappell, Vere, ed. 1998. Locke. Oxford Readings in Philosophy. Oxford: Oxford University Press.

Clarke, Desmond M., ed. 2008. Philosophical Writings. By George Berkeley. Cambridge Texts in the History of Philosophy. Cambridge: Cambridge University Press.

Finocchiaro, Maurice A. 1997. 'The Port-Royal Logic's Theory of Argument.' Argumentation 11 (4): 393-410.

Flew, Anthony. (1974) 1993. 'Was Berkeley a Precursor of Wittgenstein?' In George Berkeley: Alciphron, or the Minute Philosopher in Focus, edited by David Berman, 214-226. London and New York: Routledge.

Florka, Roger. 2004. 'Problems with the Garber-Dear Theory of the Disappearance of Descartes's Method.' Philosophical Studies 117 (1-2): 131-141.

Garber, Daniel. 1988. 'Descartes and Method in 1637.' PSA: Proceedings of the Biennial Meeting of the Philosophy of Science Association: 225-236.

Holtzman, Matthew. 2013. 'Berkeley's Theory of Common Sense.' Berkeley Studies 24:3-21.

Jesseph, Douglas M. 1993. Berkeley's Philosophy of Mathematics. Chicago: University of Chicago Press.

Jolley, Nicholas. 1999. Locke: His Philosophical Thought. Oxford: Oxford University Press.

Locke, John. 1823. The Works of John Locke. 10 vols. London: Thomas Tegg.

Malebranche, Nicolas. (1674-1675) 1997. The Search after Truth. Edited and translated by Thomas M. Lennon and Paul J. Olscamp. Cambridge Texts in the History of Philosophy. Cambridge: Cambridge University Press. 
Malebranche, Nicolas. (1688) 1997. Dialogues on Metaphysics and on Religion. Edited by Nicholas Jolley. Translated by David Scott. Cambridge Texts in the History of Philosophy. Cambridge: Cambridge University Press.

Marui, Jennifer Smalligan. 2014. 'Propositions and Judgments in Locke and Arnauld: A Monstrous and Unholy Union?' Journal of the History of Philosophy 52 (2): 255-280.

Mattern, Ruth Marie. (1978) 1998. 'Locke: "Our Knowledge, Which All Consists in Propositions".' In Chappell 1998, 226-241.

McCann, Edwin. 1994. 'Locke's Philosophy of Body.' In The Cambridge Companion to Locke, edited by Vere Chappell, 56-88. Cambridge: Cambridge University Press.

Muehlmann, Robert G. 1992. Berkeley's Ontology. Indianapolis: Hackett.

Newman, Lex. 2007a. 'Locke on Knowledge.' In Newman 2007b, 313-351. , ed. 2007b. The Cambridge Companion to Locke's "Essay Concerning Human Understanding". Cambridge: Cambridge University Press.

O'Kelley, Thomas A. 1971. 'Locke's Doctrine of Intuition Was Not Borrowed From Descartes.' Philosophy 46 (176): 148-151.

Ott, Walter. 2002. 'Propositional Attitudes in Modern Philosophy.' Dialogue 41 (3): 551-568.

Owen, David. 2007. 'Locke on Judgment.' In Newman 2007b, 406-435.

Pappas, George S. 1982. 'Berkeley, Perception, and Common Sense.' In Turbayne 1982, 3-21.

— 2000. Berkeley's Thought. Ithaca, NY: Cornell University Press. 2002. 'Abstraction and Existence.' History of Philosophy Quarterly 19 (1): 43-63.

Parigi, Silvia, ed. 2010. George Berkeley: Religion and Science in the Age of Enlightenment. International Archives of the History of Ideas 201. Dordrecht: Springer.

Passmore, J. A. (1980) 1998. 'Locke and the Ethics of Belief.' In Chappell 1998, 279-299.

Pearce, Kenneth L. 2016. 'Leibniz and the Veridicality of Body Perceptions.' Philosophers' Imprint 16 (5): 1-17.

- 2017. Language and the Structure of Berkeley's World. Oxford: Oxford University Press.

Quine, Willard Van Orman. (1935) 1976. 'Truth By Convention.' In Quine 1976, 77-106.

. (1954) 1976. 'Carnap and Logical Truth.' In Quine 1976, 107-136. 
Quine, Willard Van Orman. 1976. The Ways of Paradox and Other Essays. Revised and enlarged edition. Cambridge, Mass.: Harvard University Press.

Rickless, Samuel C. 2013. Berkeley's Argument for Idealism. Oxford: Oxford University Press.

Roberts, John Russell. 2007. A Metaphysics for the Mob: The Philosophy of George Berkeley. Oxford: Oxford University Press.

Schaar, Maria van der. 2008. 'Locke and Arnauld on Judgment and Proposition.' History and Philosophy of Logic 29 (4): 327-341.

Schwartz, Claire. 2010. 'Berkeley and His Contemporaries: The Question of Mathematical Formalism.' In Parigi 2010, 43-56.

Scott, David. 2008. 'Malebranche and Descartes on Method: Psychologism, Free Will, and Doubt.' Southern Journal of Philosophy 46 (4): 581-604.

Tipton, I. C. 1974. Berkeley: The Philosophy of Immaterialism. London: Methuen \& Co Ltd.

Turbayne, Colin Murray, ed. 1982. Berkeley: Critical and Interpretive Essays. Minneapolis: Minnesota University Press.

Van de Pitte, Frederick. 1988. 'Intuition and Judgment in Descartes' Theory of Truth.' Journal of the History of Philosophy 26 (3): 453-470.

Wilson, Margaret D. 1982. 'Did Berkeley Completely Misunderstand the Basis of the Primary-Secondary Quality Distinction in Locke?' In Turbayne 1982, $108-123$.

Winkler, Kenneth P. 1989. Berkeley: An Interpretation. Oxford: Clarendon Press.

Wittgenstein, Ludwig. 1953. Philosophical Investigations. Translated by G. E. M. Anscombe. New York: Macmillan. 